\title{
XLII. Mass of the $\alpha$ particles from thorium
}

\section{E. Rutherford F.R.S. \& O. Hahn Ph.D.}

To cite this article: E. Rutherford F.R.S. \& O. Hahn Ph.D. (1906) XLII. Mass of the $\alpha$ particles from thorium , Philosophical Magazine Series 6, 12:70, 371-378, DOI: 10.1080/14786440609463550

To link to this article: http://dx.doi.org/10.1080/14786440609463550

册 Published online: 16 Apr 2009.

Submit your article to this journal ¿

Џ Article views: 2

Q View related articles $\sqsubset$

Citing articles: 3 View citing articles 진 
The observed heating effects of the emanation and radium $A$ are given together, as it is very difficult experimentally to determine their separate effects. It will be seen that there is a substantial agreement between the calculated and observed values.

\section{Connexion between the Velocity and Amount of Tonization produced by the a particle.}

Bragg (Phil. Mag. Nov, 1905) has shown that the ionization produced by a single $\alpha$ particle increases with the distance from the source to nearly the end of its range, when the ionization falls off very abruptly. He has shown that the ionization produced by the $\alpha$ particle at a distance $r$ cms. from the end of the path is inversely proportional to $\sqrt{r+c}$, where $c$ is a constant equal to 1.33. In a previous paper (Phil. Mag. Aug. 1906) I bave shown that the velocity of an $\alpha$ particle at a distance $r \mathrm{cms}$. from the end of its range is proportional to $\sqrt{r+d}$, where $d$ is a constant equal to $1 \cdot 25$. The close agreement between these two expressions shows that the ionization produced per unit path by the $\alpha$ particle is inversely proportional to its relocity. This is in agreement with the theoretical views of Bragg, who supposed that the rate of expenditure of energy of the $\alpha$ particle in ionization at any point is inversely proportional to the energy of motion which it possesses.

A comparison of the velocities of the a particles expelled from the various products of the radio-elements, and a discussion of the connexion that exists between the velocity of expulsion of the a particle and the character of the transformation will be given in a later paper.

I desire to express my thanks to Dr. Hahn and Dr. Levin for their assistance in the measurement of the numerous photographs obtained in this investigation.

Berkeley, California, July 20, 1906.

XIII. Mass of the $\alpha$ particles from Thorium. By $\mathrm{E}$. Rutherford, F.R.S., Macdonald Professor of Physics, McGill University, Montreal, and O. HAHN, Ph.D.*

[Plate V. figs. 1-3.]

THE present investigation, which has involved the determination by the photographic method of the defexion of the a rays from the active deposit of thorium in a magnetic and electric field, has been rendered possible by

* Communicated by the Authors. 2 B 2 
the use of the highly active preparation of radiothorium, separated from the mineral thorianite by Dr. Hahn.

Radiothorium has been shown by Hahn to produce thorium $\mathrm{X}$, the thorium emanation, and the characteristic active deposit of thorium. It is a product of thorium, probably intermediate between thorium itself and thorium $X$. Radiothorium consequently exhibits to a very intense degree the characteristic radioactive properties of ordinary commercial thorium.

In previous papers (Phil. Mag. June and July, 1906) Hahn showed from an examination of the ionization curves that the active deposit of thorium emitted two distinct types of rays, one of which had a range $5.0 \mathrm{cms}$. in air, and the other a range of $8.6 \mathrm{cms}$. It has not so far been found possible to separate from each other the two a ray products from which these rays are emitted. Since the first product of the active deposit, viz. thorium $A$, is rayless, these two a ray products have been called thorium $B$ and thorium $C$. It is not so far possible to decide whether the a particles of range $8.6 \mathrm{cms}$. belong to the product $\mathrm{B}$ or $\mathrm{C}$, but, for convenience, they will be ascribed to thorium $\mathrm{C}$. The a particles of thorium $\mathrm{B}$ thus have a range in air of $5.0 \mathrm{cms}$.

Since the active deposit of thorium can be obtained in a very thin film on a fine wire, it forms a very convenient source of a rays for a determination of the deflexion of the a rays in a magnetic and electric field. Such an active wire emits two homogeneous types of rays which have ranges in air of 5.0 and $8.6 \mathrm{cms}$. respectively. Some preliminary results of the determination of the magnetic deflexion of the rays from thorium $\mathrm{C}$ have been given in a previous paper by Hahn (loc. cit.).

The apparatus employed to determine the magnetic deflexion of the rays is the same as that described in a paper of Rutherford (Phil. Mag. ante, pp.350-1). It is consequently not necessary to describe it further here. The active wire was about $1.5 \mathrm{~cm}$. long, and of diameter $0.43 \mathrm{~mm}$. The photographic plate was in all experiments $4 \mathrm{cms}$. above the active wire and within 2.5 or $2 \mathrm{cms}$. above the slit. After placing the active wire in position, the apparatus was exhausted of air.

The magnetic field, which was kept constant, was reversed every hour, and an experiment usually occupied ten hours. In this time, the activity of the source has decayed to about half of its initial value. The experiments in all cases were comparative, the magnetic deflexion of the a 
rays from radium $\mathrm{C}$ under identical conditions serving as a standard.

For this purpose, the same wire was used as a source of rays in both the thorium and radium experiments. After the wire had lost most of its activity, it was made the negative electrode in a vessel containing a large quantity of the radium emanation. The active wire, coated with a thin film of radium C, was then placed in the same position as before in the deflexion apparatus and the experiment repeated. In this case, an exposure of the plate for two hours was sufficient to obtain well-marked photographs of the traces of the deflected pencil of rays.

In order to obtain a sufficiently intense source of rays for the thorium experiment, a wire about $1.5 \mathrm{~cm}$. long was made the only negative electrode in a small closed vessel containing the highly emanating preparation of radiothorium. After two days' exposure, the activity of the wire bad nearly reached a maximum. In the preliminary experiments, the activity produced on the wire was not very intense and the photographic impression produced in a ten hours' exposure was very weak. $\mathrm{By}$ careful attention to the construction of the vessel in which the wire was made active, and by further chemical treatment of the radiothorium preparation in order to make it highly emanating, it was found possible to obtain wires sufficiently active to give a clear impression on the photographic plate under the conditions of the experiment.

\section{Magnetic Deflexion of the a rays from Thorium $B$ and $C$.}

We have seen that an examination of the ionization curves of the active deposit of thorium had disclosed the existence of two distinct a ray products, thorium $B$ and $C$, with different ranges in air. This conclusion was confirmed by an examination of the magnetic deflexion of the pencil of rays from the active wire. Two distinct sets of $\alpha$ rays were found to be present which were unequally deflected in a magnetic field. Each product emitted homogeneous rays, but the a particles from thorium $B$ had a lower velocity than those from thorium $\mathrm{C}$ and were consequently more deflected by the magnetic field than the latter. The difference in the amount of deflexion of the two sets of rays was not sufficient to obtain a complete separation of the photographic bands due to them, but the amount of deflexion of each pencil of rays could be deduced in the following manner. 
Let $\mathrm{ABC}, \mathrm{A}^{\prime} \mathrm{B}^{\prime} \mathrm{C}^{\prime}$ (Pl. V. fig. 1, a) represent the deflected bands due to the $\alpha$ rays from the wire conted with the active deposit of thorium. Each of these deflected bands consists of two distinct parts. The inside portions $\mathrm{AB}, \mathrm{A}^{\prime} \mathrm{B}^{\prime}$ are due to the a rays from thorium $\mathrm{C}$, the outer portions $\mathrm{BC}, \mathrm{B}^{\prime} \mathrm{C}^{\prime}$ to the $\alpha$ rays from thorium B. Since the rays from the latter produce less photographic effect than those from thorium $\mathrm{C}$, the outer bands $\mathrm{BC}, \mathrm{B}^{\prime} \mathrm{C}^{\prime}$ are much less clearly defined than the inner bands due to the rays from thorium C. Let EF (fig. 1, b) represent the bands obtained under identical conditions using the same wire coated with radium $\mathrm{C}$. The width $\mathrm{D}$ of the bands $\mathrm{E}, \mathrm{F}$ represents the normal width of the photographic trace due to a single homogeneous source of a rays.

Let $d_{1}, d_{2}, d_{3}$ represent twice the normal magnetic deflexions of the pencil of a rays emitted by thorium B, thorium $\mathrm{C}$, and radium $\mathrm{C}$ respectively. The distances $\mathrm{CC}^{\prime}, \mathrm{AA}^{\prime}$, are measured on the photograph in the usual way.

Then

$$
\begin{aligned}
& d_{1}=\mathrm{CC}^{\prime}-\mathrm{D} \\
& d_{2}=\mathrm{AA}^{\prime}+\mathrm{D}, \\
& d_{3}=\mathrm{EF},
\end{aligned}
$$

where $\mathbf{E}$ and $F$ are the centres of the radium bands. Now the amount of deflexion of the pencil of $\alpha$ rays is inversely proportional to the value $\frac{m u}{e}$, where $m$ is the mass of the $\alpha$ particle, $e$ its charge, and $u$ its velocity. Knowing the value of $\frac{m u}{e}$ for the a rays from radium $\mathrm{C}$ under the conditions of the experiments, the value of $\frac{m u}{e}$ for the rays from thorium $\mathrm{B}$ and $\mathrm{C}$ can at once be determined. A number of experiments were made on the magnetic deflexions of the $\alpha$ rays from the active thorium wire when covered with different absorbing layers to cut down the velocity of the $\alpha$ rays. We have seen in a previous paper that the velocity of an $\alpha$ particle which has a range $r$ ems. in air is proportional to $\sqrt{r+1 \cdot 25}$. This relation should hold for the $\alpha$ particles from thorium as well as from radium if the $\alpha$ particles in all cases have the same value of $e / m$. It is of interest to compare the observed deflexions of the a rays from thorium $\mathrm{B}$ and $\mathrm{C}$ with those to be expected from the known range of their a particles in air.

Experiment 1.-The magnetic deflexions of the $\alpha$ rays from thorium B and $\mathrm{C}$ were first determined with an unscreened 
the Mass of the a particles from Thorium.

source of radiation. The following relative values were observed :-

$$
\frac{d_{1}}{d_{3}}=1 \cdot 09 ; \frac{d_{2}}{d_{3}}=\cdot 91 ; \frac{d_{1}}{d_{2}}=1 \cdot 20 .
$$

Remembering that the ranges in air of the a rays from thorium $\mathrm{B}$, thorium $\mathrm{C}$, and radium $\mathrm{C}$ are $5.0 \mathrm{cms}$., $8.6 \mathrm{cms}$, and $7.06 \mathrm{cms}$. respectively, and that the amount of deflexion of a pencil of rays is inversely proportional to the velocity of the rays, we should expect the following values of the ratios :-

$$
\begin{aligned}
& \frac{d_{1}}{d_{3}}=\sqrt{\frac{7 \cdot 06+1 \cdot 25}{5 \cdot 0+1 \cdot 25}}=1 \cdot 15, \\
& \frac{d_{2}}{d_{3}}=\sqrt{\frac{7 \cdot 06+1 \cdot 25}{8 \cdot 6+1 \cdot 25}}=\cdot 92, \\
& \frac{d_{1}}{d_{2}}=\sqrt{\frac{8 \cdot 6+1 \cdot 25}{5 \cdot 0+1 \cdot 25}}=1 \cdot 255 .
\end{aligned}
$$

Taking into consideration the difficulty of determining the edge of the weak photographic impression due to the rays from thorium $B$, the relative velocities observed experimentally substantially agree with those deduced from the known ranges of the $\alpha$ particles. The $\alpha$ rays from thorium $\mathrm{C}$ are projected with a velocity about 9 per cent, greater than those from radium $\mathrm{C}$, while the $a$ particles from thorium $\mathrm{B}$ are projected with a velocity about 13 per cent. less than those from radium $\mathrm{C}$.

Experiment 2.-The experiments were repeated with a thickness of aluminium over the active wires equivalent in stopping-power to about 2.5 cms. of air. A good photograph was obtained which showed clearly the bands due to the rays from thorium C, bounded on the edge by the weaker bands due to the rays from thorium $B$. The effect of covering both the thorium and radium wire with the screen is to bring out more clearly the difference in velocities of the three types of rays. The actual photographs obtained are reproduced in fig. 2 A \& B. (Pl. V.) Fig. 2 a shows the thorium bands. The well-defined dark band due to the $\alpha$ rays from thorium $C$ is seen to be bounded on the outer edge by a hazy band due to the $\alpha$ rays from thorium $B$. The original negative showed the two sets of rays very clearly, but much of the definition is lost in the reproduction, which is magnified about 1.4 times. It will be seen that the corresponding radium photograph (fig. 2 в) shows two clear well-defined bands. 
The results of the measurements are given below, using the same notation as before. The values of $d_{1}, d_{2}, d_{3}$ in this case refer to the deflexions observed for the rays after passing through the aluminium screen :-

$$
\frac{d_{1}}{d_{3}}=1.32 ; \frac{d_{2}}{d_{3}}=\cdot 85 ; \frac{d_{1}}{d_{2}}=1.55 .
$$

Remembering that the ranges of the three sets of rays are each reduced $2 \cdot 5 \mathrm{cms}$. in their passage through the aluminium screen, the emerging pencils of rays from thorium $B$, thorium $\mathrm{C}$, and radium $\mathrm{C}$ have ranges of $2.5 \mathrm{cms} ., 6.1 \mathrm{cms}$, and $4.56 \mathrm{cms}$. respectively. The ratios, calculated as before, are

$$
\frac{d_{1}}{d_{3}}=1 \cdot 245 ; \frac{d_{2}}{d_{3}}=\cdot 89 ; \quad \frac{d_{1}}{d_{2}}=1 \cdot 38
$$

The calculated and experimental ratios are not in as good agreement as would be expected from the excellence of the photographs. It is not unlikely that a part of the difference is due to an accidental shift of the photographic plate in arranging the apparatus for the radium experiment.

Experiment 3.-A layer of mica equal in stopping-power to about $3.5 \mathrm{cms}$. of air was placed over the active wires. The photographic effect of the a rays from thorium B was in this case too weak for accurate measurement. The photographic intensity of an a particle appears to be approximately proportional to its range in air. The range of the $\alpha$ rays from thorium $B$ in this experiment was only $1.5 \mathrm{~cm}$, while the rays from thorium $\mathrm{C}$ had a range $5 \cdot 1 \mathrm{~cm}$. The photographic effect of the rays from thorium $B$ was consequently less than one-third of the rays from thorium $C$. 'The observed value of $\frac{d_{2}}{d_{3}}$ was 1.12 while the ratio calculated from the ranges is $1 \cdot 15$.

Experiment 4.-A layer of aluminium equivalent in stopping-power to $1.5 \mathrm{~cm}$. of air was placed on top of the mica. The interposed screens consequently corresponded to $5 \mathrm{cms}$. of air and completely cut off the rays from thorium $\mathrm{B}$. The photographs obtained are shown in fig. 3, magnification about 1.4. Fig. $3 \mathrm{~A}$ shows the bands due to thorium $C$ and fig. 3 B the bands due to radium C. The much greater deflexion of the rays from radium $C$ is obvious from an inspection of the photographs. As we should expect, there 
is no blurring of the edges of the bands due to the rays from thorium B, such as is shown in fig. $2 \mathrm{~A}$.

The observed ratio $\frac{d_{2}}{d_{3}}=\cdot 78$, while the calculated ratio $s \cdot 82$.

$$
\text { Values of } \frac{m u}{e} \text {. }
$$

Considering the difficalty of accurately measuring up some of the weak photographs obtained with the thorium rays, the observed deflexions are found to agree fairly closely with those calculated from the known ranges of the $\alpha$ particles. The calculated ratios are probably more accurate than the experimental values, and the former will consequently be used to determine the value of $\frac{m u}{e}$ for the rays from thorium $\mathrm{B}$ and $\mathrm{C}$. The value of $\frac{m u}{e}$ for the unsereened rays from radium $\mathrm{C}$ has been shown in a previous paper to be $4.06 \times 10^{5}$.

The value of $\frac{m u}{e}$ for the rays from thorium $B$ is consequentiy given $b_{y}$

$$
\frac{m u}{e}=\sqrt{\frac{5 \cdot 0+1 \cdot 25}{7 \cdot 06+1 \cdot 25}} \times 4 \cdot 06.10^{5}=3 \cdot 52 \times 10^{5} .
$$

The corresponding value for the rays from thorium $\mathrm{C}$ is given by

$$
\frac{m u}{e}=\sqrt{\frac{8 \cdot \overline{8}+1 \cdot 25}{7 \cdot 06+1 \cdot 25}} \times 4 \cdot 06.10^{5}=4 \cdot 42 \times 10^{5} .
$$

The value of $\frac{m u}{e}$ for the $\alpha$ rays from thorium $\mathrm{C}$ after their passage through the standard thickness of mica, equal to $3.5 \mathrm{cms}$. of air, is given by

$$
\frac{m u}{e}=3.53 \times 10^{5} \text {. }
$$

\section{Electrostatic Deflexion of the a rays.}

The same apparatus was used as in the radium experiments. The rays from the active wire passed through the standard mica screen and the base of the vessel. Two wires were used to obtain a measurable photographic effect, each wire 
being left two days in position in the base of the apparatus. The rays from both thorium $B$ and $C$ were present, but the photographic effect of the former was small compared with the latter, and could not be distinguished on the plate.

The electrostatic deflexion was obtained in two distinct experiments. In one case, the photographic plate was $3.94 \mathrm{cms}$. above the parallel plates and the P.D. applied was 337 volts; in the other, the distance of the photographic plate from the parallel plates was $10 \mathrm{cms}$. and the voltage 423.5 . The formula employed in the calculations have already been given in the accompanying paper by Rutherford.

In the first experiment the value of $\frac{m u^{2}}{e}$ was found to be $6.7 \times 10^{14}$, and in the second $7 \cdot 3 \times 10^{14}$. The mean value

$$
\frac{m u^{2}}{e}=7 \cdot 0 \times 10^{14}
$$

From the magnetic experiments,

$$
\frac{m u}{e}=3.53 \times 10^{5}
$$

This gives the values

$$
\begin{aligned}
u & =1.98 \times 10^{9} \mathrm{cms} . \text { per second. } \\
e / m & =5.6 \times 10^{3} .
\end{aligned}
$$

It has been shown in a previous paper that the value of $e / m$ for the $\alpha$ particle from radium is $5.07 \times 10^{3}$. Remembering that too high a value of $e / m$ is to be expected when the electrostatic deffexion of the rays is determined from a weak photograph, the agreement between the values of $\mathrm{e} / \mathrm{m}$ is sufficiently close to indicate that the $\alpha$ particle expelled from thorium $\mathrm{C}$ has the same mass as the $\alpha$ particle expelled from radium, and is jdentical with it.

The significance of this result has been discussed in the companion paper dealing with the mass of the $\alpha$ particle expelled from radium and actinium.

Berkeley, Cal.

July $30,1906$. 
Phil. Mag. Ser. 6, Vol. 12, PI. V.

RUTHERFORD. ]

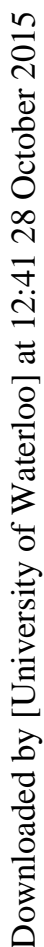

RUTHFRFord \& HAIT.
Fig. 2.

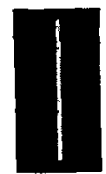

A

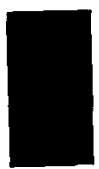

B

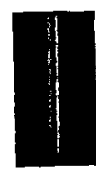

C

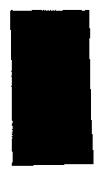

ก

FIg. 1.

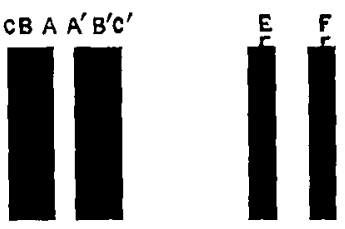

FIG. 2.

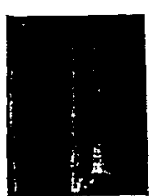

A

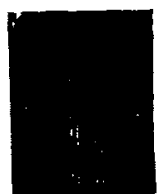

B
FIG. 3.
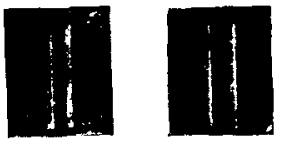

A 